\title{
EL COMBATE DE CAVITE: UN HITO DECISIVO EN LA PÉRDIDA DE FILIPINAS EN 1898
}

\author{
POR \\ AGUSTÍN R. RODRÍGUEZ GONZÁLEZ \\ IES “María Zambrano”, Leganés (Madrid)
}

El combate de Cavite fue decisivo para el destino de las Filipinas en 1898. A las tan erróneas como repetidas versiones que atribuyen la derrota española a lo anticuado de sus buques, se contraponen otras, que explican el triunfo de la escuadra norteamericana por el decisivo apoyo logístico británico, que hizo posible el ataque desde Hong Kong, por el desgaste material y moral causado por la anterior insurrección filipina y la tensa situación del archipiélago, y por los graves errores de planificación y el derrotismo de los mandos españoles.

\section{El COMBATE DE CAVITE}

Es opinión muy generalizada, incluso en monografías especializadas, que la batalla que enfrentó el 1 de Mayo de 1898 a las flotas estadounidense y española en la bahía de Manila estaba ya decidida de antemano. La visión más divulgada cree que los barcos españoles eran anticuados navíos de madera, cuyos cañones apenas alcanzaban a los, por otra parte, casi invulnerables acorazados americanos. También es lugar común afirmar que los marinos españoles lucharon hasta el fin con tanto heroísmo como destreza, aprovechando todas sus escasas posibilidades, y que el saldo respectivo de bajas pone de manifiesto la total indefensión de los españoles, con lo que se concluye en que el combate fue realmente fue un auténtico "tiro al blanco" por parte de los vencedores.

Pero, y tras una larga investigación no ya sobre el propio combate, sino sobre la gestación de ambas marinas, los medios técnicos de la 
época y otros aspectos, podemos decir que muchas de estas afirmaciones son inexactas, y otras, al menos, merecen una fuerte matización.

En efecto, los barcos españoles no eran de madera, salvo una sola excepción, ni eran tan viejos, sus cañones alcanzaban sin problemas la distancia a la que se combatió, y los buques americanos no eran invulnerables en absoluto. Por otro lado, y aunque el heroísmo esté fuera de duda, ni el mando español supo aprovechar las ventajas y medios de que disponía, ni la resistencia se prolongó al límite. Cabe destacar que ningún barco español resultó hundido por la acción del enemigo, y que las bajas de uno y otro bando no han sido establecidas, al menos hasta ahora, de forma concluyente.

Por último, debemos recordar que factores de política internacional, como la discreta pero decidida actitud británica de apoyar en la contienda a los Estados Unidos, y las consecuencias materiales y morales de la anterior insurrección tagala, jugaron un papel decisivo en muchos aspectos a la hora de explicar el resultado del combate.

\section{UN BALANCE DE FUERZAS}

Tanto se ha dicho de forma ligera o claramente errónea sobre las respectivas potencias de las dos escuadras que iban a enfrentarse, que consideramos fundamental establecer los hechos, por más que cifras y datos técnicos puedan resultar áridos para los no iniciados. Es, sin embargo, la única manera de hacer algo de luz sobre tantos tópicos ${ }^{1}$.

El jefe español, contralmirante Patricio Montojo y Pasarón, jefe del Apostadero de Filipinas, disponía de diez unidades de más de 500 toneladas de desplazamiento, aptas para un combate naval entre escuadras, aparte de una treintena de pequeños cañoneros y transportes que sólo servían para operaciones de vigilancia de costa $o$ contra la insurgencia filipina.

Los diez buques mencionados se habían botado y entrado en servicio, con las excepciones del pequeño aviso "Marqués del Duero" de 1874 y la del crucero "Velasco" de 1879 , entre 1885 y 1890 , por lo que en absoluto se puede decir que eran viejos. Incluso hoy en

1 Proyecto DGICYT PS-940050. Para los programas navales y los datos técnicos de los buques de ambas escuadras, Vid Agustín R. RodríGuez GonZález, Política Naval de la Restauración, 1895-98, Madrid, San Martín, 1988.

R.I., $1998, \mathrm{n}^{\circ} 213$ 
día, muchos de los principales buques de las grandes potencias, submarinos nucleares y portaaviones incluidos, rebasan normalmente la veintena de años de edad desde su entrada en servicio.

Todos estos buques tenían casco de hierro o acero, con la excepción del crucero "Castilla", de madera aunque con estructura metálica. Ninguno de ellos estaba blindado, pero los dos cruceros gemelos "Isla de Cuba" e "Isla de Luzón", llevaban una protección consistente en una cubierta blindada interior al casco y que, en forma de caparazón de tortuga, protegía las máquinas, calderas y pañoles (almacenes) de munición. Tal protección, normal en la época, era lo que caracterizaba a los cruceros llamados "protegidos", superiores por tanto a los que no la tenían, pero muy inferior a los auténticos acorazados y cruceros acorazados, con gruesas planchas de blindaje en los costados.

En total, la escuadra española reunía siete cruceros, de los que dos estaban protegidos, y tres grandes cañoneros. Sumaban un total de 14.000 toneladas de desplazamiento, con velocidades entre los 11 y 15 nudos, y los armaban un total de 37 piezas de 160 a $120 \mathrm{~mm}, 47$ ligeras de 90 a $37 \mathrm{~mm}$, algunas ametralladoras y 13 tubos lanzatorpedos.

La escuadra del comodoro Dewey se componía de cinco cruceros protegidos y un cañonero, con un total de 19.000 toneladas, con velocidades entre los 11 y 20 nudos, armados con 10 piezas de 203 $\mathrm{mm}, 43$ de 152 a $127 \mathrm{~mm}$ y 57 ligeras de 57 a $37 \mathrm{~mm}$, así como de 10 tubos lanzatorpedos.

Aunque, en general, los buques americanos eran más grandes, potentes y modernos que los españoles, la diferencia no era mucha, y podía ser contrarrestada por otros factores, como luego veremos. Pero lo cierto es que ni en tecnología o concepción ambas escuadras diferían en mucho.

Ninguno de los dos bandos podía esperar refuerzos sustanciales, al menos en un futuro próximo, especialmente porque se esperaba que el encuentro principal fuera en el Caribe, siendo el Pacífico un escenario secundario.

La "US Navy" sólo contaba con dos buques más en Extremo Oriente: los viejos vapores "Mohican" y "Monocacy", ambos de casco de madera, el primero un veterano de la Guerra de Secesión, botado en 1863 , con propulsión a paletas, y el segundo algo menos viejo, pero igualmente inútil para un combate naval. Los dos iban armados con viejas piezas de avancarga, por lo que , con buen criterio, se les destinó a misiones secundarias, e incluso se sacaron hom- 
bres de sus dotaciones para completar la de otros buques. Es de destacar, para deshacer tópicos, que el "Mohican" era, con mucho, el buque más antiguo de ambas escuadras, y que incluso en la estadounidense, era entonces normal el que hubiera buques de madera en servicio.

Aparte de estos buques, estaban disponibles en el Pacífico dos cruceros protegidos, el "Philadelphia" y el "Charleston", pero el primero debía permanecer en Hawaii, entonces en proceso de anexión a los EE:UU en previsión de conflictos, y el segundo se estaba preparando en las bases de la costa Oeste, y no estaría disponible hasta unos meses después. Otros dos pequeños cruceros, el "Bennington" y el "Wheeling", permanecerían patrullando la costa americana durante toda la guerra. Además se alistaban dos monitores, buques de gran potencia, pero de tan malas condiciones marineras que sólo servían para defensa de costas.

En cuanto a los españoles, y sin disminuir sensiblemente la escuadra que debía combatir en el escenario principal del Atlántico, podían haber destacado a Manila dos grandes cruceros protegidos: el "Lepanto" y "Alfonso XIII", que con sus totales de 9.000 toneladas, ocho piezas de $200 \mathrm{~mm}$, doce de $120 \mathrm{~mm}$, catorce de pequeño calibre y diez tubos lanzatorpedos, suponían una fuerza que unida a la de Montojo, hubiera sido incluso superior a la atacante. De hecho, el segundo de los citados figuró en los años anteriores como destinado en Filipinas, pero ambos buques, construidos en astilleros españoles, resultaron tan defectuosos que, tras muchos intentos, el primero fue destinado a buque-escuela, y se díó de baja por inútil al segundo tras la guerra.

En suma: ambos bandos estaban limitados, al menos en un largo período, a los buques que se han reseñado al principio, aparte de la posibilidad de artillar algún rápido y moderno vapor mercante como "crucero auxiliar".

\section{EL PESO DE OTROS FACTORES}

Existía una cierta superioridad de la escuadra norteamericana sobre la española, especialmente si el combate se producía en alta mar, pero nada obligaba a la española a ello, al contrario, su inferioridad podría verse más que compensada si se batía a la defensiva, con el apoyo de baterías de costa y de minas submarinas. 
Esto ya era importante, pero lo decisivo era el factor logístico: mientras los españoles podían combatir al lado de su base de Cavite, donde podrían reabastecerse de todo lo necesario, reparar averías, etc, con el apoyo de una ciudad como Manila, mientras que la escuadra norteamericana no tendría tales facilidades.

De hecho, una flota estadounidense que atacara Filipinas tendría en aquella época serias dificultades. En primer lugar, sus bases más cercanas estarían en la propia costa Oeste de los Estados Unidos, a más de 7.000 millas náuticas de distancia, es decir, mayor de la autonomía de sus buques, que tendrían que hacer escalas en puertos neutrales, que, según la legislación internacional, no pueden ser utilizados como base en tiempo de guerra por una escuadra beligerante.

Por todo ello, la escuadra norteamericana se lo jugaba todo a una baza y tendría que obtener un triunfo rápido y completo. Todo lo que no fuera eso sería una derrota, pues sin poder reparar averías o carbonear, a poco que se dilatasen las operaciones, la escuadra atacante tendría que retirarse a un puerto neutral y allí, en virtud de la legislación internacional, dejarse internar por el resto de la guerra, con lo que la amenaza sobre Filipinas desaparecería.

No tiene pues, nada de extraño, que incluso observadores neutrales contemplaran con escepticismo las posibilidades estadounidenses. En concreto, la marina imperial alemana informó al kaiser Guillermo que parecía probable una victoria española. A ello se añadían consideraciones sobre la mayor experiencia y tradición de la Armada española sobre la novel americana, y el hecho, bien conocido de que sus dotaciones no tendrían una gran moral de lucha, al estar compuestas en una alta proporción por extranjeros reclutados en los puertos. Y si eso pensaban los neutrales, cabe imaginar lo que sucedería entre la opinión pública española.

\section{LA ACTITUD BRITÁNICA}

Pero las tan esperables como decisivas dificultades logísticas americanas desaparecieron ante la sorprendente actitud británica.

En Enero de 1898, el "escuadrón asiático" de la marina estadounidense, al mando del comodoro Dewey, estaba fondeado en Yokohama, Japón. Dos días después de que el "Maine" entrara en La Habana, y en un marco de "guerra preventiva", Dewey recibió la orden de no 
licenciar a sus marineros que hubieran cumplido el tiempo de servicio, orden normal cuando se prevé un conflicto inmediato. El 25 de Febrero, diez días después de la explosión del acorazado en el puerto cubano, las nuevas órdenes a Dewey le señalaban dirigirse a Hong Kong, adquirir allí todo el carbón posible y prepararse para atacar Filipinas.

En la entonces colonia británica, Dewey preparó sus buques activamente para la guerra, reparándolos y poniéndolos a punto en los astilleros, adiestrando a las dotaciones e incluso, reclutando marineros para completarlas. Y a nadie se le ocultaban sus propósitos, pues se efectuaban prácticas de tiro constantes y se cambió la pintura de los buques del blanco normal en tiempos de paz al gris de guerra. También se compraron dos vapores para servir como transportes de la escuadra a la compañía británica "Peninsular \& Oriental", el "Nanshan" y el "Zafiro", así como otro más pequeño y rápido, el "McCulloch", para servir como enlace y mensajero, pues entonces aún no existía la radio.

El 22 de Abril llegó como refuerzo el crucero "Baltimore", con más municiones, siendo reparado, repintado y puesto rápidamente a punto en los astilleros de Hong Kong. Recordemos que la guerra era un hecho desde el 21 de Abril, cuando comenzó el bloqueo naval americano de Cuba. Las autoridades británicas se tomaron su tiempo para hacer salir a Dewey del puerto, en aplicación de las normas internacionales de neutralidad, y de hecho, su escuadra sólo partió el 25 de Abril. Pero eso no era suficiente para completar los preparativos, y se permitió un nuevo plazo en la bahía Mirs, entonces todavía territorio chino, y aunque ya se había acordado su cesión a Inglaterra, se retrasó el traspaso, para así permitir una nueva demora ${ }^{2}$.

Todo el asunto es muy significativo, pues según la legislación internacional entonces vigente, el que un país neutral proporcione los medios o facilite las cosas para que fuerzas armadas de una potencia ataquen a un tercer país era algo completamente ilegal. Curiosamente los británicos habían sido tradicionalmente muy puntillosos al respecto, por motivos obvios, dados sus vastos intereses marítimos. Y ya sabemos que no sólo se permitió esa preparación, sino incluso la adquisición de tres buques y la recluta de marineros. Y sobre los propó-

2 El mejor libro sobre la cuestión, aunque difiera en alguna apreciación con lo expuesto es el de Rosario de la TORRE DEL Río, Inglaterra y España en 1898, Madrid, Eudema, 1988.

R. I., $1998, \mathrm{n}^{\circ} 213$ 
sitos de la escuadra de Dewey no podía caber duda alguna i porqué entonces aquellos completos y premiosos preparativos de guerra?

Entonces Gran Bretaña argumentó que había respetado la letra de la ley al ordenar la salida de los buques americanos el día 25, aunque ya sabemos que no sin nuevas concesiones y demoras, lo que indudablemente no pudo decir es que hubiera cumplido con el espíritu de la ley. Y resulta de una ingenuidad pueril suponer que la Inglaterra victoriana hubiera dejado prepararse y facilitado toda clase de ayudas durante casi dos meses a Dewey para un ataque contra las posesiones españolas de no haber estado previamente conforme en que las Filipinas debían cambiar de manos. También resulta increíble suponer que los mandos estadounidenses contaran con tan decisiva ayuda confiando simplemente en las entonces cordiales relaciones entre los dos estados.

A nuestro entender, el gobierno británico, entre otras consideraciones, debió considerar que España tenía virtualmente perdidas las Filipinas bien por una nueva insurrección, un ataque del exterior o una combinación de ambos, y que en la perspectiva de que el estratégico archipiélago pasara a manos de una potencia rival, decidió favorecer los planes americanos. De hecho, y durante toda la guerra, hizo lo posible por asegurar el abastecimiento de la ya vencedora pero aislada escuadra de Dewey fondeada ante Manila.

Con este decisivo apoyo, lo cierto es que Gran Bretaña no sólo consintió, sino que permitió de hecho el ataque americano a las Filipinas, haciendo desaparecer con ello una de las principales ventajas españolas.

\section{LOS ERRORES ESPAÑOLES}

La composición y potencia de la escuadra atacante era perfectamente conocida en Manila, gracias a los informes del cónsul español en Hong Kong y a los de la Comisión de Marina en China, allí radicada. Y sobre sus propósitos no había tampoco grandes dudas ${ }^{3}$.

\footnotetext{
3 La documentación básica sobre las operaciones españolas en Operaciones Navales durante la Guerra con los Estados Unidos en 1898, Madrid, Imprenta del Ministerio de Marina, 1899, pp 5-81.
} 
Por ello el Capitán General Primo de Rivera convocó una reunión el 15 de marzo en el palacio de Malacañang para estudiar los planes para la defensa. Ya sabemos que se esperaba hacer un buen uso de cañones emplazados en tierra y minas para reforzar el poder defensivo de la escuadra de Montojo. Ni unos ni otras sobraban, por lo que se pidieron más a España, pero lo cierto es que no se pudieron enviar o se hizo demasiado tarde.

Pese a ello, con los recursos disponibles había más que de sobra, si hubieran sido empleados correctamente. El Ejército, como es habitual, controlaba los cañones de costa, y aunque 24 piezas eran demasiado anticuadas para ser de utilidad, se disponía de 4 obuses de $240 \mathrm{~mm}$, nueve de 210 y seis cañones de $150 \mathrm{~mm}$, algo anticuados, pero todavía perfectamente eficaces para dañar a buques sólo protegidos como los americanos. A este total la Armada podía unir otras 28 piezas procedentes de buques ya retirados, algo anticuadas, pero también eficaces. Aquellos cañones, unidos a los de la escuadra formaban un conjunto muy superior al que armaba a los barcos enemigos, sin contar con que, al estar instalados en tierra eran mucho menos vulnerables que los montados en un buque.

Existían además minas, aunque en número insuficiente y con carencia de algunos elementos, pero se fabricaron algunas más y se adquirió lo necesario para que pudieran utilizarse más de cuarenta. Operadas por la Armada, aquellos por entonces nuevos artefactos tenían efectos letales contra los barcos, pues el choque con una sola de ellas causaba el hundimiento o, al menos, gravísimas averías.

Así que, aunque no los deseables, había medios más que suficientes en Manila para rechazar a un enemigo no muy impresionante, pero los mandos españoles echaron todas sus oportunidades por la borda al carecer de un plan definido. El Ejército creía que la escuadra debía defender la ciudad de Manila, y que, por tanto, allí debían emplazarse los cañones y minas, pero Montojo consideraba que eso era poner en riesgo la ciudad, y que la escuadra se defendería mejor en la estrecha bahía de Subic, a la entrada de la de Manila.

El resultado de la polémica y de los diversos planes propuestos fue que los medios se desperdigaron completamente: los 13 obuses del Ejército se quedaron en Manila, junto a las piezas anticuadas, y los otros seis cañones modernos se repartieron mandando cuatro a Subic y dejando dos para proteger el arsenal de Cavite. Los cañones de la Armada se emplazaron en un cuarto lugar, en los islotes y flan- 
cos de las entradas a la bahía de Manila. Con las minas se hizo algo parecido: 14 fueron a Subic, 22 quedaron en la entrada a Manila y unas pocas se fondearon frente a Cavite.

Repartir así entre cuatro puntos distintos y sin posible apoyo los recursos existentes era desperdiciarlos, cuando si hubieran sido concentrados en cualquiera de ellos hubieran podido dar la victoria. Montojo siguió aferrado a la opción de Subic, pero al comprobar el 25 de Abril que allí sólo se había instalado un cañón y alguna mina, decidió en el último momento presentar batalla en Cavite.

\section{LA SITUACIÓN DE LA ESCUADRA}

Para colmo de males, la situación operativa de los buques era bastante mala. Agotados por las largas navegaciones y combates necesarios para derrotar a la anterior insurrección, unido a las ya extenuantes labores de vigilancia del extenso archipiélago, de Marianas y Carolinas, los buques necesitaban reparación y puesta a punto, y las tripulaciones, castigadas por las bajas y las enfermedades, necesitaban refuerzos y entrenamiento para un combate naval, pues era un tipo de operación que no se había dado con los insurrectos.

Es cierto que faltaba el dinero en la endeudada España, y que no se podían mandar muchos refuerzos pues el cántaro ya había ido demasiado a la fuente, pero algo más se pudo hacer, como veremos. Tampoco el arsenal de Cavite tenía la capacidad para efectuar rápida y eficazmente reparaciones, por lo que se solía enviar a los buques mayores a reparar a Hong Kong. Se había adquirido un moderno dique flotante para facilitar las obras, pero aún no había llegado.

Todo ello era cierto, pero Montojo agravó considerablemente estos males con su actuación. Obsesionado con la idea de mantener el orden en las islas, siguió enviando todavía a primeros de Abril a los cruceros a sofocar rebeliones en puntos tan alejados como Visayas y Mindanao, y gastaba sus no muy abundantes recursos en la compra de lanchas de vapor para vigilancia costera, mientras dirigía largas peroratas al Ministro de Marina sobre el tipo mejor de pequeño cañonero para vigilancia de costas. $Y$ todo ello cuando sabía perfectamente que un enemigo mucho más peligroso podía llegar en cualquier momento. 
En vez de desgastarse aún más en operaciones irrelevantes, los buques de la escuadra hubieran debido concentrarse en Cavite, repararse y alistarse en lo posible, hacer maniobras de conjunto y realizar prácticas de tiro, prohibidas por cierto por Montojo para no gastar municiones, criterio erróneo donde los haya, pues la mejor manera de ahorrarlas era justamente mejorar la puntería, y unos pocos tiros de prácticas mejoran sensiblemente el rendimiento en combate. En cuanto a los conatos de insurrección, hubiera hecho mejor en enviar a sofocarlos a los transportes armados y a los pequeños cañoneros, sin utilidad en un combate naval entre escuadras, reservando y preparando a los cruceros.

Así, de las diez unidades reseñadas, tres no podían navegar: los cruceros "Velasco" y "Ulloa" y el gran cañonero "Lezo", uno más, el "Elcano", fue dejado con poco criterio en la siempre revuelta Mindanao, y para colmo de males, al "Castilla" se le abrió una vía de agua poco antes de la batalla, y aunque pudo ser reparada, el arreglo provisional impedía que el buque pudiera hacer funcionar sus máquinas.

Por todo ello, la escuadra que finalmente fondeó frente al arsenal de Cavite esperando a la enemiga se reducía a siete buques, de los que dos, el "Castilla" y el "Ulloa", en reparaciones y con la artillería y dotación reducidas, estaban privados de movimientos. Su poder artillero se había reducido igualmente a sólo 29 piezas de 160 a 90 $\mathrm{mm}$ y siete tubos lanzatorpedos. En cuanto a las baterías de costa sólo pudieron apoyarla los dos cañones del Ejército instalados en Punta Sangley para proteger el arsenal, uno de los cuales no podía disparar por su emplazamiento en la dirección en que apareció el enemigo. Tampoco había más que unas pocas minas frente a Cavite y su escaso número hacía poco creíble que resultaran eficaces. Es de imaginar que la moral de las tripulaciones, con todos aquellos despropósitos, era todo menos buena.

\section{El COMBATE}

Dewey, por su parte también bien informado sobre sus enemigos, reconoció Subic, al no encontrar allí a la escuadra española, decidió forzar la entrada a la bahía de Manila de noche, las baterías de la entrada apenas pudieron hacer algún disparo y ninguna mina estalló 
con lo que la escuadra norteamericana penetró en la bahía de Manila sin sufrir ni una sola baja ${ }^{4}$.

A eso de las cinco menos cuarto ambos adversarios se divisaron, rompiendo el fuego los españoles media hora después cuando la distancia era de unos 6.500 metros, que no fue contestado por los atacantes hasta que el alcance se redujo a menos de 5.000. Este dato, por sí solo desmiente ya la reiterada leyenda de que los cañones españoles no alcanzaban la distancia a que se hallaban sus enemigos. Lo cierto es que el cañón más común en la escuadra española, el modelo González Hontoria de $120 \mathrm{~mm}$, llegaba a los diez kilómetros de alcance.

Pero además, en la época, los rudimentarios sistemas de puntería impedían hacer blanco por encima de los cinco kilómetros, por ello, y aunque las piezas tuvieran alcances superiores, sólo se abría fuego a distancias inferiores, y en Cavite, las distancias fueron aún menores: entre poco más de 4.000 metros y la mitad de esa cifra, es decir, a distancias que incluso las piezas más pequeñas y las ametralladoras podían salvar.

El combate pronto se generalizó, dando sucesivas pasadas los seis buques americanos en hilera frente a los siete españoles, que excesivamente juntos y parados o moviéndose lentamente, presentaban un magnífico blanco. Realmente, y debido a los errores españoles, la superioridad artillera americana era más que evidente y pronto se hizo notar. Montojo decidió lanzar un ataque con torpedos, y eso hizo valientemente con su buque insignia el "Cristina", seguido del "Juan de Austria", el otro único buque de la escuadra que podía moverse y disponía de tubos. Pero el "Cristina" no tardó en ser alcanzado por un fuerte fuego enemigo que le hizo retroceder averiado e incendiado.

Curiosamente los americanos creyeron que entonces uno o dos pequeños torpederos habían participado en el ataque, e incluso creyeron haberlos hundido. Lo cierto es que se trataba de una lancha de vapor desarmada que llegaba entonces al arsenal desde las bocas de la bahía para avisar de la llegada del enemigo, y el barquito tuvo la suerte de no ser alcanzado por proyectil alguno. Por lo demás no había ningún torpedero español destinado en Filipinas.

\footnotetext{
4 Las comunicaciones y partes de la escuadra de Dewey en Appendix to the Report of the Chief of the Bureau of Navigation, Washington, Navy Department, 1898, pp 65-148.
} 
El combate duraba ya unas dos horas cuando, y ante los aliviados ohjos de los españoles, la escuadra de Dewey se retiró a eso de las 7' 35 de la mañana. El comodoro americano declaró posteriormente que aquella retirada se debió a que, según un informe erróneo, apenas le quedaban municiones.

Tal afirmación no ha podido sostenerse cuando se conocieron todos los datos, pues el error pudo haberse subsanado inmediatamente y volver al combate, sin embargo Dewey se retiró a reconsiderar la situación e incluso ordenó se diera de comer a sus agotadas tripulaciones que llevaban en pie toda la noche.

El testimonio de uno de sus ayudantes es mucho más clarificador, por lo que merece la pena ser reproducido por extenso:

\begin{abstract}
“Cuando nos retiramos de la lucha, a las 7' 30 de la mañana, Dewey se encontraba en una situación grave. Durante más de dos horas habíamos combatido a un enemigo determinado y valiente sin haber conseguido disminuir el volumen de su fuego. Es verdad que tres, por lo menos, de sus barcos están ardiendo, pero también lo estaba uno de los nuestros, el "Boston". Y los incendios habían sido extinguidos sin daño visible a los buques. En general, nada importante había ocurrido que nos permitiera decir que habíamos causado serios daños a los buques españoles. Seguían navegando por detrás de Punta Sangley o en la bahía de Bacoor con la misma actividad que cuando, al amanecer, les dimos vista por primera vez. Hasta entonces nada demostraba que el enemigo fuera menos capaz de defender su posición que lo era al comienzo".

"Por otra parte, nuestra situación había grandemente empeorado. Las municiones que quedaban en el "Olympia" no hacían posible prolongar la batalla por otras dos horas...Si se nos agotaban las municiones, podríamos ser los cazados en vez de los cazadores"

"No exagero diciendo que cuando nos retiramos, la consternación en el puente del "Olympia" era más sombría que una niebla de Noviembre en Londres"5.
\end{abstract}

Estas razones parecen mucho más creíbles, especialmente porque concuerdan perfectamente con los hechos. Pese a su superioridad, la escuadra americana había sido incapaz en más de dos horas de combate de aniquilar a su débil oponente.

\footnotetext{
5 Testimonio de J.L Stickney, apud, Pablo de AzCÁRATE, La Guerra del 98, Madrid, Alianza, 1968, pp. 79-80.

R.I., $1998, \mathrm{n}^{\circ} 213$
} 
Efectivamente, tres de los buques españoles habían sufrido un duro castigo, los inmóviles "Castilla" y "Ulloa" y el buque insignia "Cristina", pero los incendios estaban casi apagados o bajo control, y los tres buques seguían disparando. El "Duero" y el "Austria" tenían pequeños daños, y en cuanto a los dos protegidos "Isla de Cuba e "Isla de Luzón", estaban prácticamente intactos. Para tan escasos resultados, los atacantes habían consumido casi la mitad de su munición, y como atestiguaba el incendio del "Boston" o un impacto directo en el "Baltimore", hechos ambos observados desde los buques españoles, habían sufrido también daños y averías.

En este "impasse" del combate, Dewey debió reflexionar sobre lo temerario de la misión que se le había encomendado. Cabe suponer lo que hubiera sucedido de hallarse los buques españoles en mejores condiciones y de haber dispuesto, como pudieron, del apoyo de una treintena de piezas de costa, algunas de grueso calibre, en vez de la solitaria que había apoyado a la escuadra. Incluso así, y dadas las dudas de su enemigo, Montojo podía haber jugado con el temor de su enemigo y forzar una resistencia que hubiera obligado a una retirada a Dewey, que hubiera debido retirarse a un puerto neutral, vencido de hecho aunque hubiera causado más daños y bajas de los que había recibido.

Pero Montojo, que había lavado sus errores anteriores con su gallarda conducta en el combate, perdió entonces la cabeza. Desembarcó con el motivo de hacerse curar una contusión en la pierna, ya curado, ordenó al jefe del arsenal, Sostoa, que se echaran los buques a pique si volvía el enemigo, tras extremar la resistencia, tras lo cual, se marchó por tierra a Manila, dejando a sus hombres frente al enemigo. Este hecho le valió ser encausado después de la guerra y apartado del servicio, lo que tal vez fue un castigo leve para una falta semejante.

Aquello hundió la moral de las tripulaciones, el "Castilla" y el "Cristina" fueron evacuados, y entonces se reactivaron sus incendios, ocasionando la voladura de ambos. Animado Dewey por el espectáculo, volvió al combate a eso de las 11'15, pero ya no encontró apenas resistencia, pues las tripulaciones hundieron los bar$\cos$ y se refugiaron en el arsenal. Sólo continuaron haciendo fuego los dos cañones de Punta Sangley, hasta que visto que era imposible cualquier tipo de resistencia, se izó la bandera de parlamento a eso de las 2'30 de la tarde. 


\section{UN JUICIO DEL COMBATE}

Debemos dejar un momento la narración de los hechos para analizar lo que había sucedido en el combate. Lo primero que llama la atención es la escasa puntería americana, pues de 5.859 disparos, bastantes realizados ya sin oposición, cuando los españoles habían abandonado sus buques, sólo acertaron con 141. La cifra se estableció después de la guerra por expertos americanos que reconocieron exhaustivamente los cascos de los navíos españoles.

Con mucho, el mayor castigo lo recibieron los inmóviles "Ulloa " y "Castilla" así como el insignia "Cristina", del resto, ya sabemos que el "Austria" y el "Duero" recibieron algunos daños y los "Cuba" y "Luzón" habían quedado prácticamente indemnes. De hecho, los "Austria", "Cuba" y "Luzón" fueron reflotados tras la guerra, reparados e incorporados a la US Navy, donde sirvieron largos años conservando sus nombre españoles. El primero lo hizo hasta 1921, en que fue vendido como mercante, durando hasta 1932, el segundo hasta 1912, siendo luego revendido a la marina venezolana, donde sirvió hasta 1929, y el tercero hasta 1919, para llegar como mercante hasta 1931. Realmente no eran tan malos ni viejos como se ha dicho, ni sufrieron tanto en el combate.

En cuanto a las bajas humanas, se han exagerado o confundido continuamente, lo cierto es que se conservan listas nominales completas y revisadas, que además concuerdan con los partes de los médicos. El total suma 60 muertos y 222 heridos en la escuadra, 17 muertos y 49 heridos en el arsenal y un herido en uno de los buques inútiles allí fondeados. Desglosadas por buques son muy significativas, pues sólo entre el "Cristina" y el "Castilla" sumaron 52 de los 60 muertos y 186 de los 222 heridos en la escuadra, lo que prueba que fueron casi los objetivos únicos del enemigo. El total de tripulantes era de 1.144 , lo que supone un porcentaje global de más de un $20 \%$, de ellas, 14 muertos y 42 heridos corresponden a marineros filipinos ${ }^{6}$.

Bastantes de estas bajas se produjeron no en el combate propiamente dicho, sino en el bombardeo posterior del arsenal y cuando

\footnotetext{
6 Los datos sobre blancos americanos en Effect of the gunfire of the US Vessels in the Batle of Manila Bay, Washington, Office of Intelligence, 1899, los de las bajas españolas en Archivo de la Armada D.Alvaro de Bazán, Fondos de Cartagena, Filipinas, legajo R II b y en Histórico, leg 4838.
}

R. I., $1998, \mathrm{n}^{\circ} 213$ 
los españoles ya no se defendían. De hecho, eso explica el elevado número de bajas entre el personal del arsenal, mayoritariamente filipinos, que también pudo verse aumentado por represalias de sus compatriotas insurrectos de la vecina provincia de Cavite, cuando, tras la victoria americana, invadieron tumultuosamente el arsenal.

En cuanto a los vencedores, anotaron 25 impactos españoles en sus buques, la mayoría de pequeño calibre, lo que desmiente de nuevo la versión de que estaban fuera de alcance. Aquellos proyectiles eran demasiado ligeros para causar graves averías en un buque, pero que los navíos americanos no eran invulnerables, lo demostró uno de los escasos proyectiles de calibre medio, de $120 \mathrm{~mm}$, que hizo blanco. La granada atravesó de parte a parte al crucero "Baltimore", el segundo más grande de su escuadra, rebotó en la cubierta blindada, y dando un extraño quiebro, volvió a salir por el mismo costado por el que había penetrado; pese a que no llegó a estallar por algún defecto en la espoleta, desmontó dos cañones del buque, hizo estallar una caja de munición ligera y causó nueve heridos. Ya sabemos también que el "Boston" tuvo un incendio en cubierta.

Lo cierto es que, pese a que se ha afirmado lo contrario, la puntería española dejó que desear, pues hubieran sido esperables muchos más blancos. La cuestión se explica por falta de personal adiestrado, por la falta de práctica, y porque se estimó por exceso la distancia al enemigo, ya que se creyó erróneamente que no se acercaría tanto.

En cuanto a las bajas, la cuestión no está tan clara como entre los españoles, tras varios partes contradictorios, se reconoció oficialmente un total de 1 muerto y doce heridos, cifras que rechazaron los españoles presentes, que afirmaron que los americanos ocultaban las suyas, y basándose en fuentes neutrales, las estimaron al menos en 13 muertos y 30 heridos. Tal vez Dewey quiso realmente ocultar las bajas a una opinión pública muy recelosa ante la aventura filipina, y para ello las camufló entre los doce muertos por enfermedad de su escuadra en la campaña, o las nada menos que 155 deserciones. Ya sabemos que muchos de sus marineros no eran ciudadanos norteamericanos, y a nadie le importaría demasiado el destino de uno de ellos, especialmente si era asiático, como era corriente entre fogoneros y los puestos más humildes.

Pese a todo ello, la desproporción salta a la vista, pero cosas semejantes han sucedido desde entonces en combates navales, incluso a primera vista más igualados. Las nuevas técnicas navales tenían 
mucho que ver con ello, pero hasta entonces se carecía de experiencia. La Primera Guerra Mundial fue clarificadora al respecto: en la batalla de Coronel, una escuadra alemana hundió a una inglesa causándola 1.650 muertos por sólo dos heridos alemanes, pero sorprendida esa misma escuadra vencedora por una superior británica en las Malvinas poco después, el porcentaje se invirtió, con más de dos mil muertos alemanes por sólo nueve bajas británicas.

\section{El EPÍlOGo}

Asegurada ya su victoria, los buques americanos se dedicaron a incendiar los buques españoles, que debido al poco fondo, sobresalían del agua como si estuvieran a flote. Aparte de los siete que combatieron, se perdieron así los inútiles "Velasco" y "Elcano", el pequeño buque hidrográfico "Argos" y alguno más, aparte del vapor de la Trasatlántica "Isla de Mindanao" y el transporte de la Armada "Manila", que fue apresado prácticamente intacto.

Al día siguiente, y tras arduas negociaciones, Dewey aceptó la capitulación de los refugiados en el arsenal, que podían salir libres y dirigirse a Manila, dejando sus heridos al cuidado de los vencedores, lo que no fue un detalle muy digno, por cierto. Así cayó prácticamente intacto en manos de los americanos el arsenal y base, justamente de lo que carecían. Si Montojo estaba tan seguro de la derrota como dijo después, no tiene disculpa el que no previera su voladura antes de entregarlo a un enemigo cuya principal debilidad era que carecía de una base de operaciones.

Pero aún peor: en la capitulación se incluyó a las baterías de la entrada a la bahía de Manila, por lo que poco después, los trescientos hombres que las defendían abandonaron sus cañones y se refugiaron igualmente en Manila sin apenas haber hecho más que un par de disparos inútiles la noche anterior. Las de Subic siguieron su ejemplo poco después, y en cuanto a las de Manila, permanecieron silenciosas ante la amenaza de Dewey de bombardear la ciudad en caso contrario.

Todo aquello consiguió el comodoro tras un combate de dos horas, del que se retiró creyendo que lo tenía perdido o poco menos, tras averiar sólo a tres de los siete buques que se le enfrentaban. El resto de los éxitos se los proporcionó no su fuerza o estrategia, sino

R. I., 1998, $\mathrm{n}^{\circ} 213$ 
el derrotismo y la pasividad de sus enemigos. Con tan pequeño esfuerzo, había eliminado no sólo la escuadra enemiga y se había apoderado de una vital base, sino que había suprimido o silenciado las baterías de costa. Así había eliminado de un golpe todas las defensas marítimas del enemigo y situado a la capital bajo la amenaza constante de sus cañones, aislándola del exterior. Ya sólo quedaba el trámite de que tropas de desembarco o los insurrectos animados por la llegada de Aguinaldo en un buque de su escuadra, decidieran a los españoles a una capitulación antes de que los males fueran mayores.

Tales hechos cayeron como una losa sobre la moral de lucha en Manila y su guarnición: lo malo no es que se hubiera perdido una batalla, sino que se había llegado a esa derrota por la imprevisión y falta de planes claros del mando. Lo peor no era, pese a todo, que se hubieran perdido la escuadra y las baterías, lo verdaderamente desmoralizador era comprobar cómo se habían perdido.

Aquello contrastaba vivamente con la imagen que tenían de sí los españoles de la época, allí no había nada del espíritu de viejas glorias, aunque fueran derrotas. La sensación fue tan fuerte que se prefirió esconder los hechos tras épicos cantos al heroísmo de los marinos y lamentos sobre la enorme potencia y perfidia del enemigo. Y por si faltaba algo, se adobó todo con las referencias a los buques de madera con cañones ineficaces y a los invulnerables buques del enemigo.

The battle of Cavite was decisive for the fate of the Philippines in 1898. Erroneous recurrent versions attribute the Spanish defeat to their old-fashioned vessels. Other versions, however, explain the North-american victory on the basis of arguments such as the decisive British logistic support which made possible the atack from Hong Kong; the moral and material erosion caused on the Spanish troops by the previous philippine insurrection; the tensions within the archipielago; serious mistakes as regards planification, and the sense of defeatism with which the Spanish high officers were seized. 